\title{
Photocatalytic degradation of Direct Yellow-27 by photolysis with UV-light and solar irradiation Using $\mathrm{N}$-doped $\mathrm{TiO}_{2}$
}

\section{Deliza ${ }^{1,2}$, Safni ${ }^{2}$, Diana Vanda Wellia ${ }^{3}$, and Toyohide Takeuchi ${ }^{4}$}

${ }^{1}$ Integrated Laboratory Islamic State University Sulthan Thaha Saifuddin Jambi, Indonesia, 36657 ${ }^{2}$ Laboratory of Applied Analytical-Chemistry, Department of Chemistry, Faculty of Mathematics and Natural Sciences, Andalas University, Indonesia, 25163

${ }^{3}$ Laboratory of Material Chemistry, Department of Chemistry, Faculty of Mathematics and Natural Sciences, Andalas University, Indonesia, 25163

${ }^{4}$ Laboratory of Chemistry Biomolecular Science, Deparment Enginering, Gifu University, Japan, 501-1193

\section{Abstract}

Degradation of Direct Yellow-27 has been investigated using irradiation process of UV light and solar by adding of $\mathrm{N}$-Doped $\mathrm{TiO}_{2}$ catalyst. The aims of this research were to

Corresponding Author:

Deliza

deliza@uinjambi.ac.id

Received: 19 February 2019

Accepted: 5 March 2019

Published: 16 April 2019

Publishing services provided by

Knowledge E

(c) Deliza et al. This article is distributed under the terms of the Creative Commons

Attribution License, which permits unrestricted use and redistribution provided that the original author and source are credited.

Selection and Peer-review under the responsibility of the ICBSA Conference Committee. explore the optimum condition of $\mathrm{N}$-Doped $\mathrm{TiO}_{2}$ catalyst, and to test the best process of irradiation that used to degrade of Direct Yellow-27. The absorbances of sample were measured by using UV-Vis Spectrophotometer $(\lambda=300-800 \mathrm{~nm})$. The conditions of before and after degradation were quantified by using lon Chromatography. Direct Yellow-27 was successful degradated using the irradiation procces of UV light (10 watt, $\lambda=365 \mathrm{~nm}$ ) and solar (28.000 lux) with and without using $\mathrm{N}$-Doped $\mathrm{TiO}_{2}$ catalyst. The result of this study showed that solar irradiation was better than UV light in process of degradation. The degradation process of direct Yellow-27 was destitute N-Doped $\mathrm{TiO}_{2}$ catalyst $8,72 \%$, while by adding of $\mathrm{N}$-Doped $\mathrm{TiO}_{2}$ catalyst $52,86 \%$. The catalyst optimum mass in this study was $10 \mathrm{mg}$. The liquid Chromatography analysis represented the broadening of peak that notices Diret Yellow-27 was successful degradated.

Keywords: Direct Yellow-27, UV-light, Solar irradiation, N-Doped $\mathrm{TiO}_{2}$, Photocatalyst, liquid Chromatographic

\section{Introduction}

The waste of Silungkang tenun songket dye [1, 2], West Sumatra as Direct Yellow-27 is a non-biodegradle compound that consists azo. That carcinogenic subtance could cause distrubtion in human body such as harmfull of kidney, cancer [3-5], and tumor 
advanced treatment, so that dye does not enter to river that is used by society. Without waste treatment, there will be a potential damage to river flow so it can not be used for mankind consumption [6, 7].

Several methods were used in dye treatment such us biodegradation [8], adsorption [9], coagulation, and reverse osmosis but these methods were not active for immersion waste cleaning [9]. The method mentioned above was non destructive. These methods only change the waste into another phase so it still has a negative impacts such as unefficiency, non-biodegradradation, carcinogenic [10-13].

In other ways there are more efficient and promising methods to resolve dye textiles such us photolysis [5], ozonolysis [4, 11], solar irradiation and sonolysis [14, 15] with and without catalyst addition where it decomposes organic dye coumpont into the simplest compount using photon and catalyst $[10,11,16]$.

The Previous research were used un-doped $\mathrm{TiO}_{2}$ catalyst, whereas $\mathrm{TiO}_{2}$ catalyst has broader band gab 3,2 and $4.0 \mathrm{ev}$ for anatase and rutil, prespectively [17, 18]. These conditons were active in iradiation $\mathrm{UV} \lambda<380$. Due to this situation, $\mathrm{TiO}_{2}$ Catalyst has no ability for absorbtion at UV-Light range so the catalyst were modified the chemistry structure for gaining of best catalyst. One of modification technique in $\mathrm{TiO}_{2}$ alteration is a doping using metal and non metal element so it can used in lower energy. In that condition, the performance of catalyst occurs a shifting of spectrum adsorption from UV light into Visible light. Nitrogen is the most effective dopant to be used on $\mathrm{TiO}_{2}$ catalysts because it has a small ionization energy, its size is not much different from the oxygen element and can also narrow the gap energy so that the potential is enough to be used to synthesis of $\mathrm{N}$ - Doped $\mathrm{TiO}_{2}$ [3] catalyst which is expected to be active in the light region looks and efficiently uses solar irradiation as a light source and breaks the chain of compounds in Direct azo dye into simple compounds that are not dangerous if it is channeled into the water $[16,17,19,20]$.

Previous research has been done regarding dye degradation. Such as Direct Red23 and Direct Violet Color Degradation through Ozonolysis Process and UV Light Photolysis and solar irradiation Using N-Doped $\mathrm{TiO}_{2}$ Catalyst with the addition of 20 mg N-Doped $\mathrm{TiO}_{2}$ catalyst Direct Red-23 can be degraded 55.44\% while Direct Violet can be degraded by $50 \%$ [11]. Showing good results, however, no one has used Diret Yellow-27 [7] dyestuff. In this study, direct yellow dye degradation was carried out by utilizing UV lamps and solar irradiatin. 


\section{Materials and Methods}

\subsection{Study area}

This research was conducted in Laboratorium of Applied Analytical-Chemistry, Department of Chemistry, Faculty of Mathematic and Natural Sciences, Andalas University.

\subsection{Equipments}

Spectrophotometer UV-Vis (S.1000 Secoman Sarcelles, Franch), UV-lamp (Germicidal CE G 13 Base BFC11004, $\lambda=365 \mathrm{~nm}, 10$ Watt), box iradiasi, sentrifuse $10.000 \mathrm{rpm}$, petridish, dan glasess equipments.

\subsection{Materials}

Direct Yellow-27 dye $\left(\mathrm{C}_{25} \mathrm{H}_{20} \mathrm{~N}_{4} \mathrm{Na}_{2} \mathrm{O}_{9} \mathrm{~S}_{3}, \mathrm{Mr}=662,62 \mathrm{~g} / \mathrm{mol}\right)$ (Fig. 1) from silungkang Industry, distiled water, $\mathrm{N}$-doped $\mathrm{TiO}_{2}$, capillary column, silica $\mathrm{C} 18$, methanol, acetonitrile, Politetrafluoroetilen. All other reagents were of analytical grade. A Direct Yellow-27 [7, 21] stock solution of $2 \mathrm{~g} \mathrm{~L}-1$ was prepared by dissolving an accurately weighed amount of Direct Yellow-27 in distilled deionized water. Test solutions of Direct Yellow-27 were prepared by diluting the stock solution with distilled deionized water. In this work, the initial Direct Yellow-27 concentration (Co) varied from 7 to $293 \mathrm{mg} \mathrm{L-1}$, and the pH of each solution was adjusted to the desired value using $0.1 \mathrm{M} \mathrm{HCl}$ or $\mathrm{NaOH}$ solutions [22].<smiles>COc1ccccc1NC(=O)C(N=Nc1ccc(-c2nc3ccc(C)c(S(=O)(=O)O[Na])c3s2)cc1[SH](=O)(O)O[Na])=C(C)O</smiles>

Figure 1: Structure of Direct Yellow-27. 


\subsection{Prepare and measurement of dye absorption spectra}

$0.015 \mathrm{gr}$ sample were soluted into $250 \mathrm{~mL}$ aquadest to get $40 \mathrm{mg} / \mathrm{L}$ solution, next Direct Yellow-27 solution were measured for the absorbance using UV-Vis spektrophotometer $(\lambda 300-800 \mathrm{~nm})$. The absorbance data were taken at maximum absorbance $\lambda$.

\subsection{Degradation of dye by UV-Light and solar irradiation un catalyst}

Direct Yellow-27 solution were poured into 5 diferent petridish. The solution were degraded with UV-Light and solar irradiation in 30 minutes interval. Degredated solutions were measured for absorbance by UV-Vis spektrophotometer.

The degradation percentage of dye from solution at different time interval and condition is show as:

$$
\% \text { Deg } \frac{A o-A t}{A o} \times 100 \%
$$

Where Ao is the initial absorbance of Direct Yellow-27 and At is absorbance of Direct Yellow-27 at different condition. The effect of $\mathrm{N}$-doped $\mathrm{TiO}_{2}$ amount on glass substrate and irradiation time on photodegradation of Direct Yellow-27 was tested.

\subsection{The effects of $\mathrm{N}$-doped $\mathrm{TiO}_{2}$ catalyst variation on dye degradation for optimum condition using UV-light and solar irradition}

Direct yellow-27 solution were poured into 5 diferent petridish, furthemore $5-25 \mathrm{mg}$ catalyst the solution were added and degraded with UV-Light and solar irradiation during 2 hours. Result of degradation was centrifuged at a speed of $10.000 \mathrm{rpm}$ to separate the catalyt. The absorbance of solution that has been degraded measured bg UV-Vis spektrophotometer.

\subsection{Prepare a column C.18 liquid chromatography}

The separation column was prepared using a fused silica capillary tube with a length of $100 \mathrm{~mm}$ with a size of $0.32 \mathrm{~mm} \mathrm{I.D} \mathrm{and} 0.45 \mathrm{~mm}$ O.D. stationary phase material is inserted into the capillary column by dissolving $\mathrm{C} 18$ using methanol. Then testing the 
ability of the column using the acetonitrile mobile phase. The chromatographic system circuit scheme used in the study can be seen in Fig. 2 .

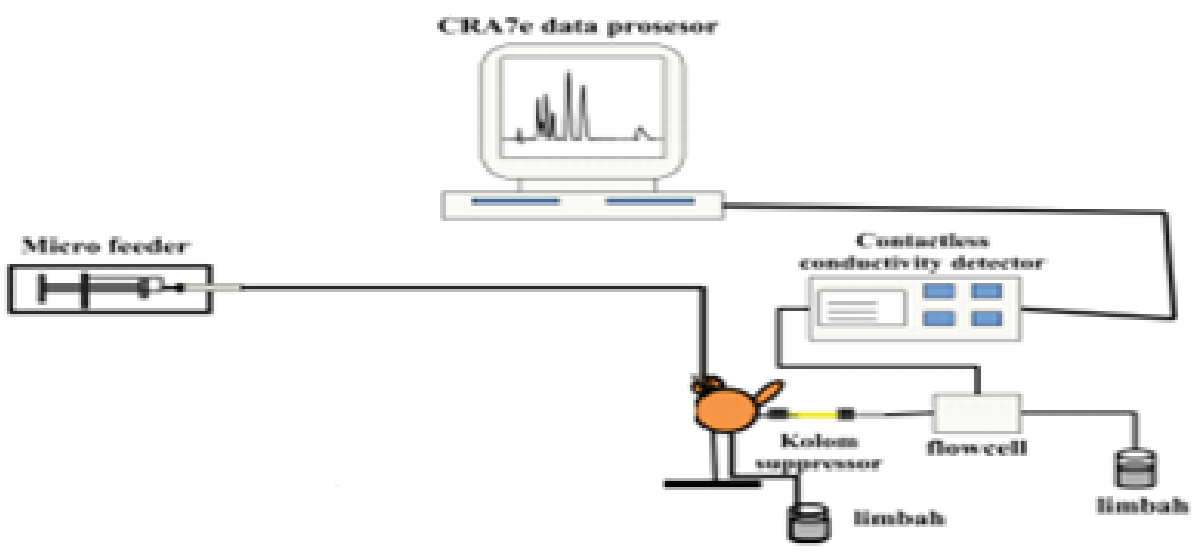

Figure 2: Schematic of Chromatography Column.

\section{Result and Discussion}

\subsection{Determination of the optimum weight of $\mathrm{N}$-doped $\mathrm{TiO}_{2}$ catalyst in the degradation process}

The solution was measured by using UV-Vis Spectrophotometer at a wavelength range of 300-800 nm, obtained a maximum absorption peak at a wavelength of $398 \mathrm{~nm}$ and absorbance of 0.820 abs. Catalysts has an important role in degradation, because they produce hydroxyl radicals. The optimum weight of $\mathrm{N}$-doped $\mathrm{TiO}_{2}$ catalyst can be seen in Fig. 3, the curve that showed relationship between percent degradation with the weight of $\mathrm{N}$-doped $\mathrm{TiO}_{2}$ catalyst.

The percent degradation of Direct Yellow-27 solution increased increasing number of $\mathrm{N}$-doped $\mathrm{TiO}_{2}$ is shown in Fig. 3. Because the increasing amount of catalyst causes the active side of the surface to increase so that the number of photons and molecules of dyes absorbed [23].

It can be seen in the optimum weight curve of $\mathrm{N}$-doped $\mathrm{TiO}_{2}$ catalyst, which was 10 mg where it can degrade by $53.13 \%$ After 120 minutes. But at the addition of a catalyst weight of more than $10 \mathrm{mg}$, the percent degradation will decrease. This is due to the increase in the amount of catalyst so that the turbidity of the solution increases so as to reduce the light that is transmitted to the degradation process $[3,24,25]$. 


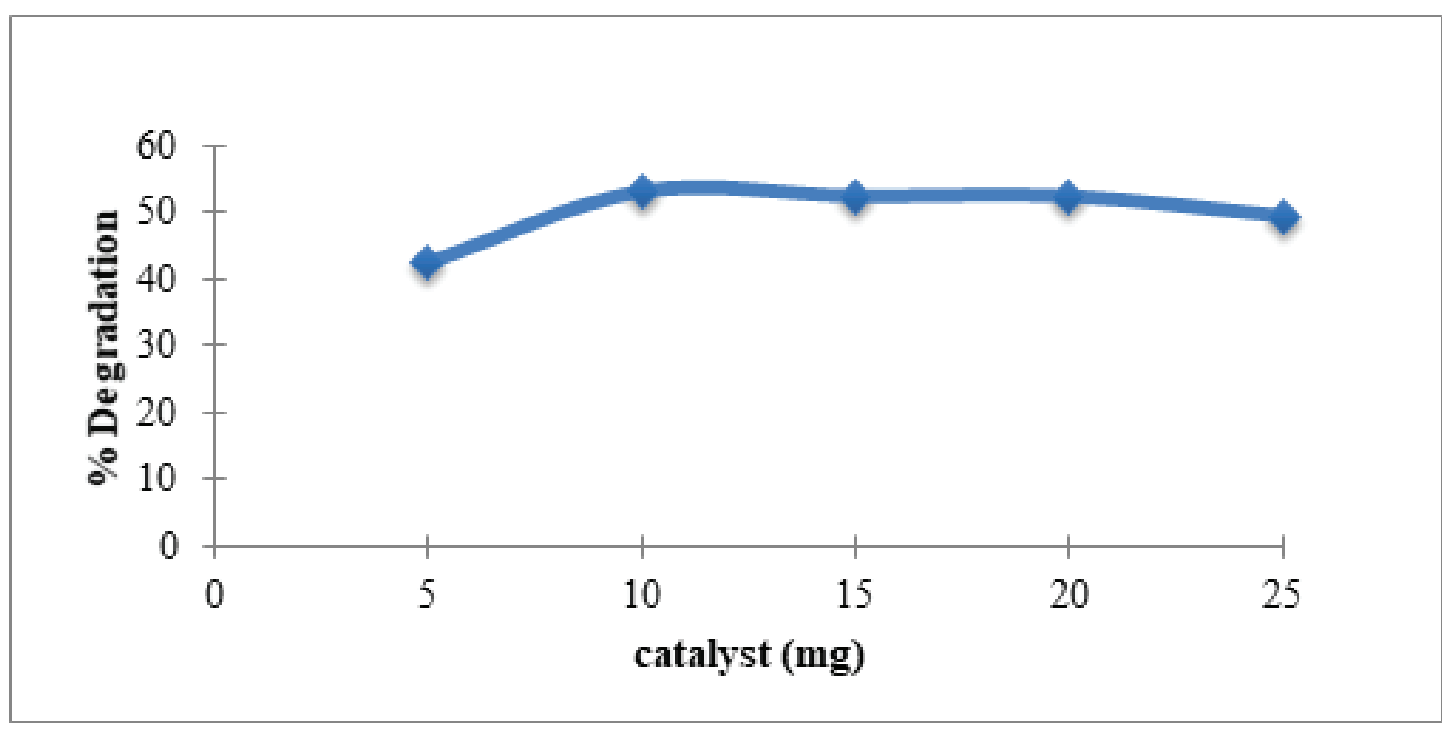

Figure 3: The correlation curve between $\mathrm{N}$-doped $\mathrm{TiO}_{2}$ catalyst weight and degradation percentage from Direct Yellow-27.

A semiconductor can undergo a photoinduced process upon irradiation. This will consist of the promotion of one electron from the VB to the $\mathrm{CB}$, leaving a hole in the valence band and thus creating the photogenerated $\mathrm{e}^{-} / \mathrm{h}^{+}$pair $[18,26,27]$. This process takes place when light with wave- length within the energy range of the semiconductor bandgap interacts with the solid. After that, charge carriers can migrate from the bulk $[28,29]$ to the surface of the material. When this occurs in an aqueous medium, dissolved oxygen can be adsorbed [30,30-32] on the surface of the photocatalyst and reduced by elec- trons, giving rise to superoxide radical anions, $\mathrm{O}^{-}$(Eq. 1), while holes can oxidize water as well as hydroxyl anions, producing hydroxyl radicals, $\mathrm{HO}$ (Eqs. 2 and 3 , respectively). Furthermore, $\mathrm{O}^{-}$can form hydroperoxyl radicals, $\mathrm{HOO}$, by protonation (Eq. 4). These oxidant radical species allow the mineralization of the pollutants (Eq. 5). Nevertheless, "scavenging" reactions can also take place (Eqs. 6-8), including the recombination of charges (Eq. 9), which reduces the efficiency of the photocatalyst.

$$
\begin{gathered}
\left(\mathrm{O}_{2}\right) \text { ads }+\mathrm{e}^{-} \rightarrow \mathrm{O}_{2}^{\bullet-} \\
\mathrm{H}_{2} \mathrm{O}+\mathrm{h}^{+} \rightarrow \mathrm{HO}^{\bullet}+\mathrm{H}^{+} \\
\mathrm{OH}-+\mathrm{h}^{+} \rightarrow \mathrm{HO}^{\bullet} \\
\mathrm{O}_{2}^{\bullet-}+\mathrm{H}^{+} \rightarrow \mathrm{HOO}^{\bullet}
\end{gathered}
$$




$$
\begin{gathered}
\mathrm{HO}^{\bullet}+\mathrm{H}^{+}+\mathrm{e}^{-} \rightarrow \mathrm{H}_{2} \mathrm{O} \\
\mathrm{HOO}^{\bullet}+\mathrm{HOO}^{\bullet} \rightarrow \mathrm{H}_{2} \mathrm{O}_{2}+\mathrm{O}_{2} \\
\mathrm{HOO}^{\bullet}+\mathrm{H}^{+}+\mathrm{e}^{-} \rightarrow \mathrm{H}_{2} \mathrm{O}_{2} \\
\mathrm{e}^{-}+\mathrm{h}^{+} \rightarrow \text { hv (heat) }
\end{gathered}
$$

Where P: Pollutant [33]

\subsection{Effect of UV-Light irradiation time on the percentage of degra- dation without addition of catalyst}

Direct Yellow-27 irradiated with a 30 minute interval using UV light $\lambda=365 \mathrm{~nm}$. The effect of photolysis time on the percentage of degradation without addition of catalyst can be seen in Fig. 4.

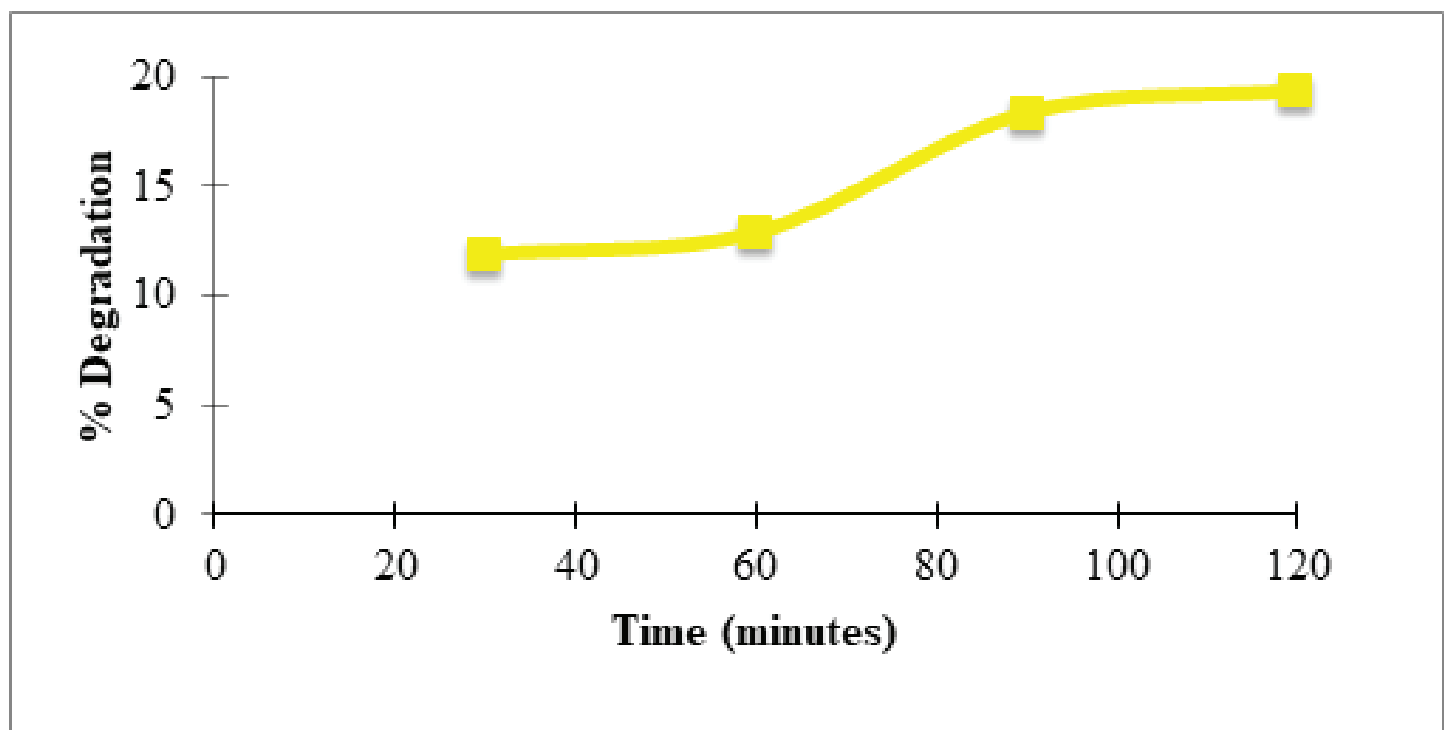

Figure 4: Effect of irradiation time on the percentage of Direct Yellow-27 degradation without catalyst.

From Fig. 4, it can be seen that the change in percentage of Direct Yellow-27 degradation increased with increasing irradiation time, because the longer the irradiation time, the more compounds that are broken down by the energy of UV light in the degradation process form $\mathrm{OH}$. Where the biggest percentage of degradation lies in the irradiation for 120 minutes which is $19.32 \%$ [34]. 


\subsection{Comparison of percentage of non-catalyst degradation and addition of $\mathrm{N}$-doped $\mathrm{TiO}_{2}$ catalyst}

Percent ratio of Direct Yellow-27 degradation between without catalyst and by adding $10 \mathrm{mg}$ of $\mathrm{N}$-doped $\mathrm{TiO}_{2}$ catalyst photolysis with UV lamp $\lambda=365$ and increasing degradation time can be seen in Fig. 5 .

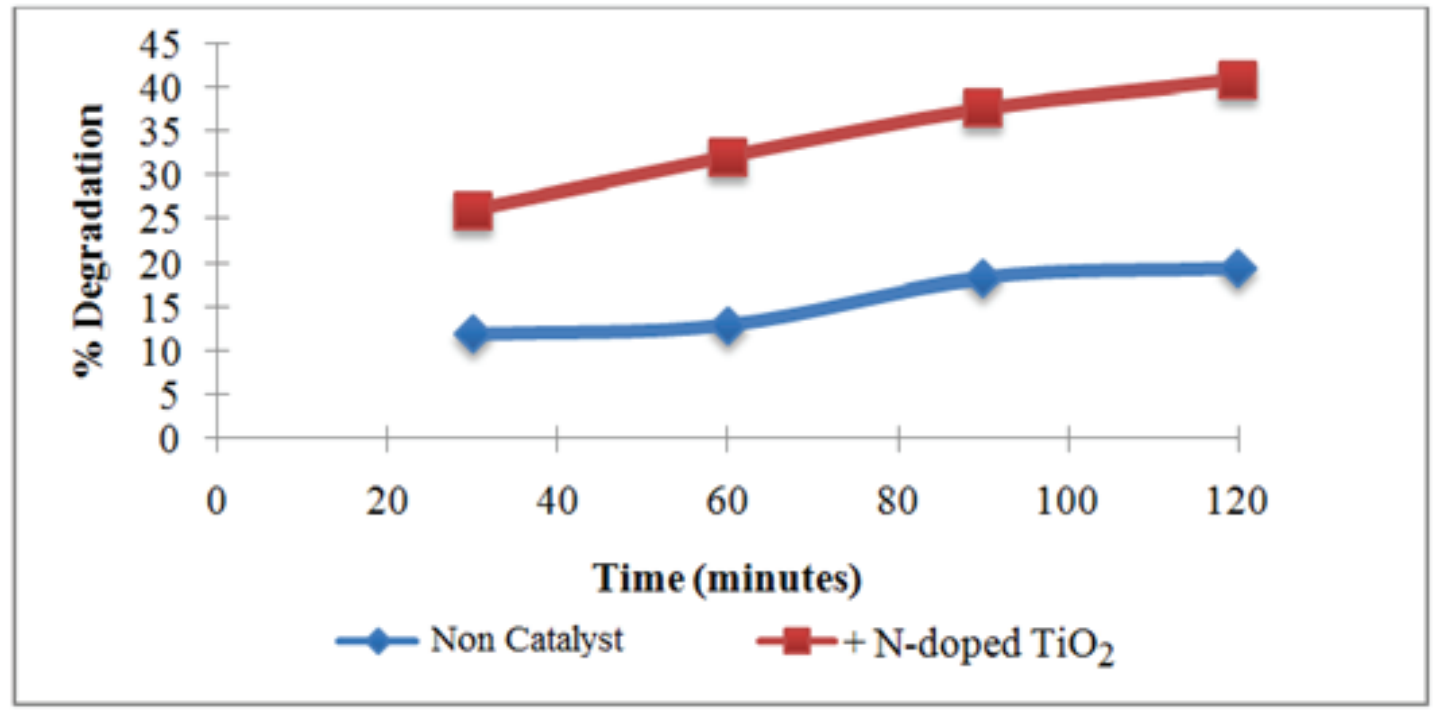

Figure 5: The effect of time on the percentage of Direct Yellow-27 degradation with the addition of N-doped $\mathrm{TiO}_{2}$ catalyst.

It can be seen from Fig. 5 that the longer the irradiation time, the more Direct Yellow27 dyes were degraded. This is because the longer the irradiation time, the more UV light is affected by the $\mathrm{N}$-doped $\mathrm{TiO}_{2}$ catalyst, so that more $\mathrm{OH}$ is produced. Being able to degrade Direct Yellow-27 increased by $40.77 \%$.

From the data it can be concluded that the percentage of Direct Yellow-27 degradation with the addition of catalyst is better than without catalyst due to excitation, due to UV light which affects $\mathrm{N}$-doped $\mathrm{TiO}_{2}$ so that the electrons in the catalyst are excited from the valence band $(\mathrm{vb})$ to the conduction band $(\mathrm{cb})$ generate holes $\left(\mathrm{hvb}^{+}\right)$in the valence band and in the conduction band $\left(\mathrm{ecb}^{-}\right)$Then the electrons in the conduction band $\left(\mathrm{ecb}^{-}\right)$react with oxygen to produce superoxide ions $\left(\mathrm{O}_{2}^{-}\right)$, then react with water to form $\mathrm{OH}$ which will break the bond dyestuffs and produce simpler compounds [23, 34, 35].

\subsection{Effect of irradiation time on the percentage of degradation without the addition of catalyst}

Solar irradiation Direct Yellow-27 with 30 minute intervals. 


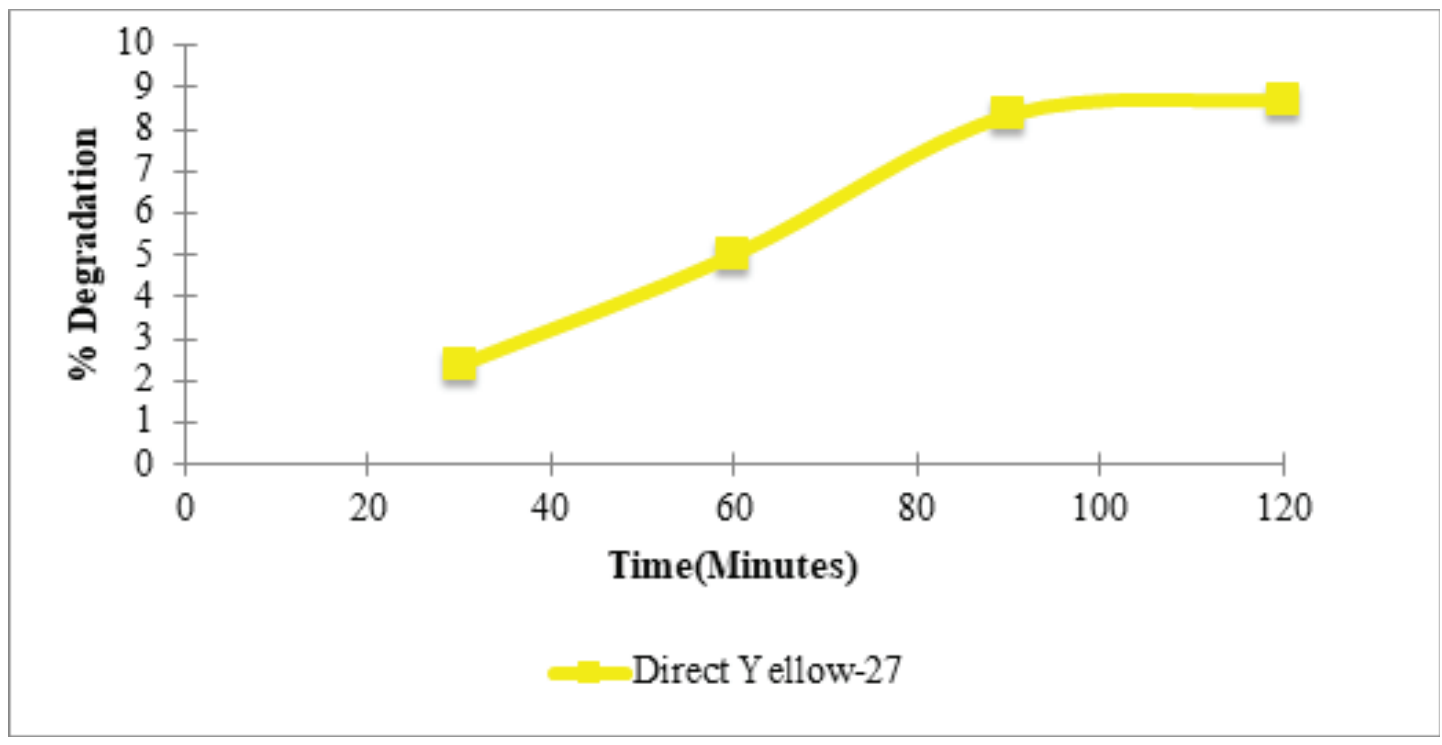

Figure 6: The effect of irradiation time on the percentage of degradation without the addition of catalyst.

From Fig. 6 it can be seen that Direct Yellow-27 dye substance was degraded by the sun irradiation method of $8.72 \%$ for 120 minutes when the dye solution was subjected to light, splitting water molecules produces $\mathrm{OH}$, which can break the bond of organic compounds $[4,5]$.

\subsection{Comparison of percentage of non-catalyst degradation and addition of $\mathrm{N}$-doped $\mathrm{TiO}_{2}$ catalyst}

Comparison of percent degradation of Direct Yellow-27 between without and addition of $\mathrm{N}$-doped $\mathrm{TiO}_{2}$ catalyst with irradiation time interval 30 minutes.

From Fig. 7 it can be seen that Direct Yellow-27 dyestuff was degraded by the sun irradiation method, but when compared with no catalyst, the percent degradation was greater when adding catalyst. Because of the ability to degrade sunlight energy with a more active catalyst and greater percent degradation [36]. The sun irradiation method was able to degrade Direct Yellow-27 by $52.86 \%$ for 120 minutes.

\subsection{Analysis liquid cromatography}

In Fig. 8 shown the measurements of Direct Yellow-27 in several treatments before and after degradation with the addition of $\mathrm{N}$-doped $\mathrm{TiO}_{2}$ catalyst which was then tested with liquid chromatography $[37,38]$ with its own assembly column. Liquid chromatography test results of Direct Yellow-27 solution were carried out by solar irradiation method as 


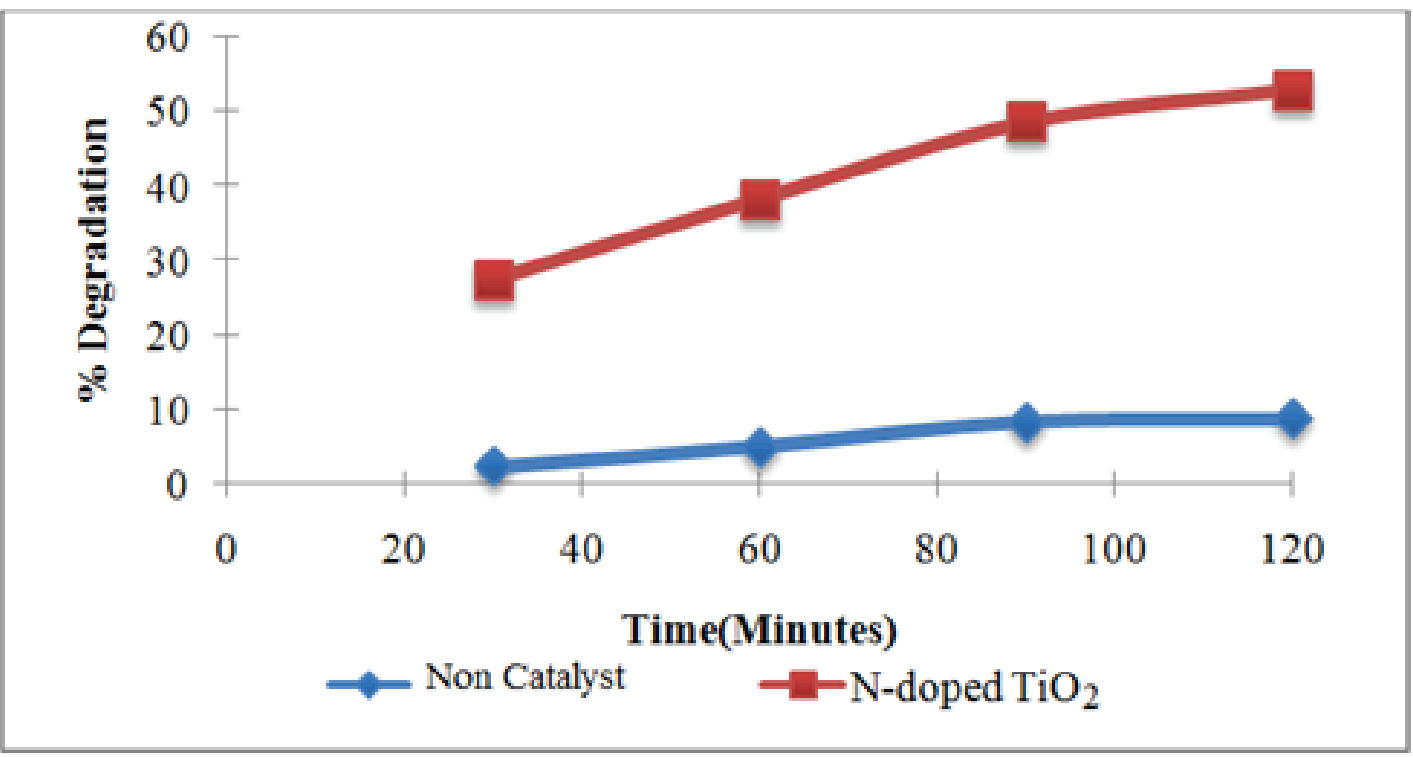

Figure 7: The effect of time on the percentage of Direct Yellow-27 degradation with the addition of N-doped $\mathrm{TiO}_{2}$ catalyst.

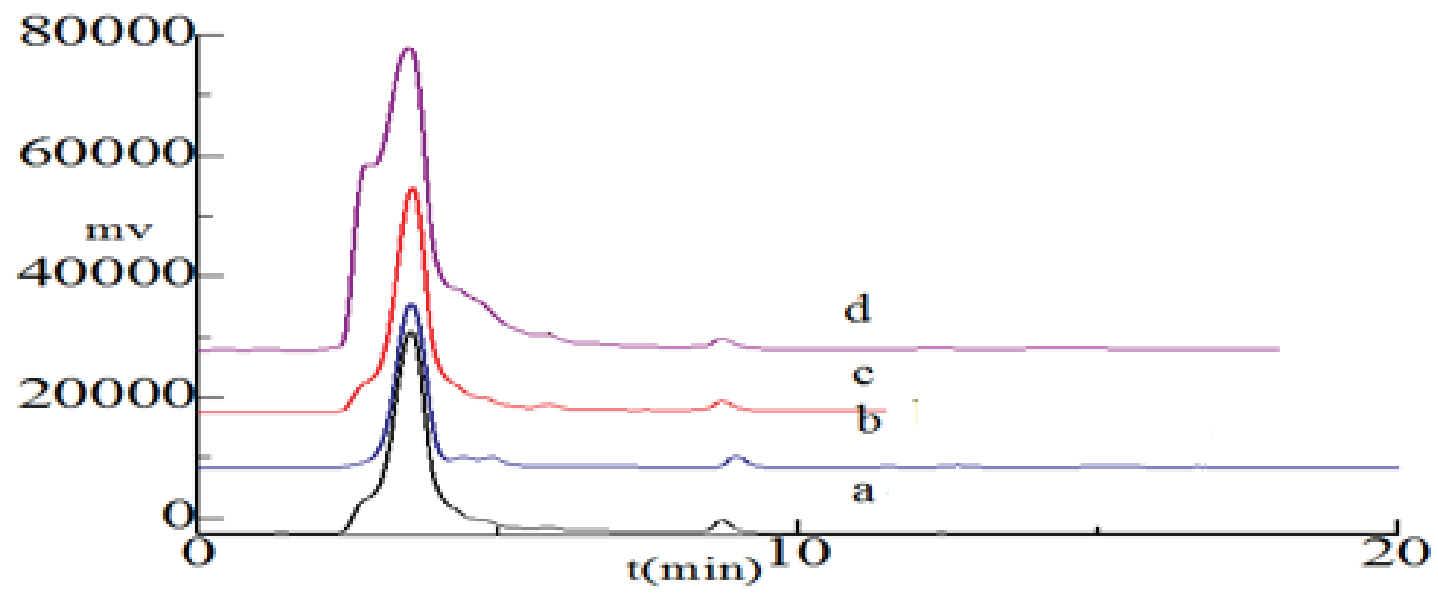

Figure 8: Direct Yellow-27 dye chromatogram (60 mg/L) (a) before degradation (b) 1 hour without catalyst degradation (c) 1 hour degradation by adding $\mathrm{N}$-doped $\mathrm{TiO}_{2}$ catalyst (d) 2 hours of degradation with addition of $\mathrm{N}$ catalyst -doped $\mathrm{TiO}_{2}$.

one of the supporting data of the research. From the Fig. shows the peak widening of the chromatogram indicates the success of Direct Yellow-27 degraded through solar irradiation [39-41].

\section{Conclusions}

$\mathrm{N}$-Doped $\mathrm{TiO}_{2}$ was proven to increase the efficiency of photolysis process in Direct Yellow-27 degradation in UV light and solar irradiation, the most efficient photolysis 
process with the largest percent degradation was photolysis with the addition of $\mathrm{N}$ doped $\mathrm{TiO}_{2}$ catalyst using solar irradiation and confirmed dye degradation through liquid chromatography.

\section{References}

[1] S. Yuhandri, Madenda, E.P. Wibowo, Int. J. Adv. Sci. Eng. Inf. Technol. 7 (2017) 235241

[2] n. indictor and a. and j. summerfield d. montegut, Numerous, 27 (1996).

[3] S.N.R.I. Panagiotis G. Smirniotis, Thirupathi Boningari, Devaiah Damma, Catal. Commun. 113 (2018) 1-5.

[4] S. Safni, Deliza, D. Anggraini, R.S. Dewi, H. Ulia, D.V. Wellia, Der Pharma Chem. 8 (2016) 30-35.

[5] S. Safni, D. Vanda Weillia, P. Sri Komala, R. Audina Putri, Der Pharma Chem. 8 (2016) 642-646.

[6] Zaharia Carmen and Suteu Daniela, in:, D.T. Puzyn (Ed.), Text. Org. Dye. Characteristics, Polluting Eff. Sep. Proced. from Ind. Effluents - A Crit. Overv., InTech, Romania, 2012, pp. 56-83.

[7] R.P.F. Melo, E.L.B. Neto, M.C.P.A. Moura, T.N.C. Dantas, A.A.D. Neto, H.N.M. Oliveira, J. Water Process Eng. 7 (2015) 196-202.

[8] S. Chakraborty, B. Basak, S. Dutta, B. Bhunia, A. Dey, Bioresour. Technol. 147 (2013) 662-666.

[9] S. Jain, R. V Jayaram, Desalination 250 (2010) 921-927.

[10] N. Jaafarzadeh, A. Takdastan, S. Jorfi, F. Ghanbari, M. Ahmadi, G. Barzegar, J. Mol. Liq. 256 (2018) 462-470.

[11] K. Safni, Deby Anggraini, Diana Vanda Wellia, J. Litbang Ind. 5 (2015) 123-130.

[12] M. Punzi, A. Anbalagan, R.A. Börner, M. Jonstrup, B. Mattiasson, Chem. Eng. J. 270 (2015) 290-299.

[13] F.R. Furlan, L. Graziela, D. Melo, A.F. Morgado, A. Augusto, U. De Souza, S. Maria, A. Guelli, U. De Souza, Resour. Conserv. Recycl. 54 (2010) 283-290.

[14] C. Belver, J. Bedia, A. Go, M. Pen, in:, Chem. Eng. Sect. Univ. Auton. Madrid, Madrid, Spain Photocatal., 2019, pp. 581-651.

[15] M. Konyar, T. Yildiz, M. Aksoy, H.C. Yatmaz, K. Öztürk, Chem. Eng. Commun. 204 (2017) 705-710. 
[16] J. Ananpattarachai, P. Kajitvichyanukul, S. Seraphin, J. Hazard. Mater. 168 (2009) 253-261.

[17] A. Lee, J.A. Libera, R.Z. Waldman, A. Ahmed, J.R. Avila, J.W. Elam, S.B. Darling, Adv. Sustain. Syst. 1 (2017) 1-6.

[18] T.P.Y. and J.C.S. Spencer P. Pitre, ChemComm (2017) 1-5.

[19] H.C. Lee, H.S. Park, S.K. Cho, K.M. Nam, J. Bard, J. Electroanal. Chem. 819 (2017) $38-45$.

[20] V. Vaiano, O. Sacco, D. Sannino, P. Ciambelli, Appl. Catal. B Environ. 170-171 (2015) 153-161.

[21] M.K. Giri, N. Jaggi, (2010).

[22] C. Material Safety Data Sheet Direct Direct Yellow-27Identification, in:, 1910, pp. 1-7.

[23] P. V. Kamat, Acc. Chem. Res. 50 (2017) 527-531.

[24] M.R. Hoffmann, S.T. Martin, W. Choi, D.W. Bahnemann, Chem. Rev. 95 (1995) 69-96.

[25] J. Wang, D.N. Tafen, J.P. Lewis, Z. Hong, A. Manivannan, M. Zhi, M. Li, N. Wu, (2009) $12290-12297$.

[26] J.T. Adeleke, T. Theivasanthi, M. Thiruppathi, M. Swaminathan, T. Akomolafe, A.B. Alabi, Appl. Surf. Sci. 455 (2018) 195-200.

[27] R.M.Cristie, in:, R.M.Cristie (Ed.), Woodheed Publ. Text., 2007, pp. 1-253.

[28] Z. He, Y. Xia, B. Tang, J. Su, Z. pHYS. cHEM (2018) 1-13.

[29] A. Chauhan, S. Thirumalai, R.V. Kumar, Mater. Today Commun. 17 (2018) 371-379.

[30] A. Mukimin, H. Vistanty, N. Zen, A. Purwanto, K.A. Wicaksono, J. Water Process Eng. 21 (2018) 77-83.

[31] G. Sanzone, M. Zimbone, G. Cacciato, F. Ru, R. Carles, V. Privitera, 123 (2018) 394402.

[32] H. Zhu, R. Jiang, Y. Fu, R. Li, J. Yao, Appl. Surf. Sci. 369 (2016) 1-10.

[33] A. Fujishima, T.N. Rao, D.A. Tryk, J. Photochem. Photobiol. A Chem. 1 (2000) 1-21.

[34] M. Nasirian, M. Mehrvar, J. Environ. Sci. 66 (2017) 81-93.

[35] d A.F.N. Andreia Morais, a Claudia Longo, a Joyce R. Araujo, b Monica Barroso, c James R. Durrant, R. Soc. Chem. 18 (2016) 2608-2616.

[36] N.E. Fahmi Arifan, FS Nugraheni, Hafiz Rama Devara, Earth Environ. Sci. 116 (2018).

[37] D. Kanakaraju, C.A. Motti, B.D. Glass, M. Oelgemöller, Chemosphere 139 (2015) 579_ 588.

[38] C. Bradu, M. Magureanu, V.I. Parvulescu, J. Hazard. Mater. 336 (2017) 52-56.

[39] Arnold R.Lang, in:, 2009. 
[40] P.J. Hauser, Textile Dyeing, CROATIA, 2011.

[41] E.T. Helmy1, Ahmed El Nemr1, * M.M., E. Arafa3, S. Eldafrawy, J. Water Env. Nanotechnol 3 (2018) 116-127. 